\title{
Jacqueline Risset, Une certaine joie. Essai sur Proust
}

\section{Geneviève Henrot Sostero}

\section{(2) OpenEdition \\ Journals}

\section{Edizione digitale}

URL: http://journals.openedition.org/studifrancesi/5748

DOI: $10.4000 /$ studifrancesi.5748

ISSN: 2421-5856

\section{Editore}

Rosenberg \& Sellier

\section{Edizione cartacea}

Data di pubblicazione: 1 septembre 2011

Paginazione: 451

ISSN: 0039-2944

\section{Notizia bibliografica digitale}

Geneviève Henrot Sostero, «Jacqueline Risset, Une certaine joie. Essai sur Proust», Studi Francesi [Online], 164 (LV | II) | 2011, online dal 30 novembre 2015, consultato il 13 janvier 2021. URL: http:// journals.openedition.org/studifrancesi/5748 ; DOI: https://doi.org/10.4000/studifrancesi.5748

Questo documento è stato generato automaticamente il 13 janvier 2021.

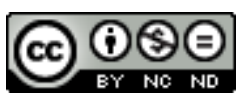

Studi Francesi è distribuita con Licenza Creative Commons Attribuzione - Non commerciale - Non opere derivate 4.0 Internazionale. 


\title{
Jacqueline Risset, Une certaine joie. Essai sur Proust
}

\author{
Geneviève Henrot Sostero
}

\section{NOTIZIA}

JACQUELINE RISSET, Une certaine joie. Essai sur Proust, Paris, Hermann, 2009 («Lettres»), 135 pp.

1 Con questo breve saggio, l'A. ripropone, uniti in un unico slancio di lettura, diverse riflessioni sgranate negli anni: dal 1974 con Théorie et fascination, seguito da Le Peu de sens du désir, Métamorphoses du mal, Éclairs dans la nuit. Le carnet de 1908, "Ce que c'est qu'un endroit de la terre», fino a Les Rêves e infine Sommeil d'une pomme. Questa fedeltà critica ad una passione di lunga data si sprigiona già dal titolo, sottilmente polifonico: se "una certa gioia" cita l'estasi proustiana di fronte agli innumerevoli "oggetti ermeneutici" studiati da Jean-Pierre Richard e da Gilles Deleuze, l'espressione, senza ombra di dubbio, contiene anche il piacere della lettura quale l'A. dimostra di averlo sempre provato, sia da poetessa e da psicanalista che da critico, ma anche il piacere di ogni lettore aperto all'appetito vitale di Proust per il mondo e per lo sguardo umoristico di cui conviene avvolgerlo. Il saggio non si vuole studio scientifico universitario, bensì piuttosto quaderno di viaggio in cui consegnare intuizioni personali e ricezione intima dell'opera, in ascolto dei punti più attivi dell'opera proustiana. Lo testimonia una breve bibliografia aperta ai vari campi d'interesse dell'A., dalla poesia alla psicanalisi, ma invece relativamente impermeabile all'evoluzione contemporanea dell'abbondantissima critica proustiana. 